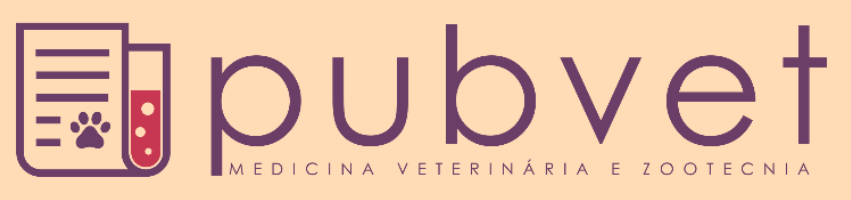

https://doi.org/10.31533/pubvet.v12n12a233.1-4

\title{
Diagnóstico do perfil do consumidor de carne de búfalo no município de Marabá, PA
}

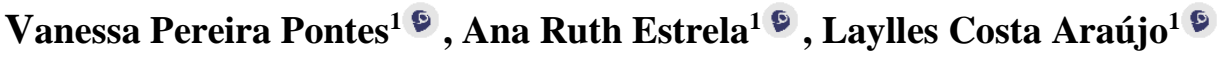 \\ ${ }^{I}$ Departamento de Produção e Nutrição de Ruminantes, Universidade Estadual do Oeste do Paraná (UNIOESTE), Rua Pernambuco, 1777 - Caixa Postal \\ 91, CEP 85960-000, Marechal Cândido Rondon, Paraná, Brasil. \\ *Autor para correspondência, E-mail: vaneppontes@gmail.com.
}

RESUMO. Este trabalho foi conduzido com o objetivo de diagnosticar o perfil do consumidor de carne de búfalo no município de Marabá-PA quanto ao conhecimento do produto e os fatores relacionados à escolha, periodicidade e quantidade de carne consumida. O diagnóstico foi realizado por meio de entrevistas com formulários online. Houve preferência no consumo de carne bovina e peixes, e a carne de búfalo mostrou-se a menos consumida, porém, uma parcela expressiva da população afirmou estar disposta a aumentar este consumo. Os motivos para não consumir carne de búfalo foram relacionados ao fato de ser uma carne pouco apreciada e falta de oferta. O desconhecimento das formas de criação, procedência, aspectos nutricionais, e possíveis formas de se comprar e preparar a carne de búfalo levou a ratificar o seu baixo consumo local, além da falta de oferta do mercado. Os consumidores de carne de búfalo consideram este um alimento saboroso e saudável, entretanto, pouco ofertada no mercado. Sugerem-se campanhas que visem o aumento da oferta e do consumo da carne de búfalos e em ações que permitam à população descobrir novas formas de preparo, consumo e mais informações nutricionais.

Palavras chave: bubalinocultura, consumo de carne, produtos processados

\section{Diagnosis of the buffalo meat consumer profile in the municipality of Marabá, PA}

\begin{abstract}
The objective of this work was to diagnose the buffalo meat consumer profile in Marabá-PA in terms of product knowledge and factors related to the choice, periodicity and quantity of milk and meat consumed. The diagnosis was made through interviews with online forms. There was a preference in beef and fish consumption, and buffalo meat was the least consumed, but a significant portion of the population said they were willing to increase this consumption. The reasons for not consuming buffalo meat were related to the fact that it was a little appreciated meat and lack of supply. The ignorance of the ways of breeding, origin, nutritional aspects, and possible ways of buying and preparing the buffalo meat has ratified its low local consumption, besides the lack of market supply. Consumers of buffalo meat consider this a tasty and healthy food, however, little offered on the market. Campaigns are suggested that aim to increase the supply and consumption of buffalo meat and in actions that allow the population to discover new forms of preparation, consumption and more nutritional information.
\end{abstract}

Key words: bubalinoculture, meat consumption, processed products 


\title{
Diagnóstico del perfil del consumidor de carne de búfalo en el municipio de Marabá, PA
}

\begin{abstract}
RESUMEN: Este trabajo fue conducido con el objetivo de diagnosticar el perfil del consumidor de carne de búfalo en el municipio de Marabá-PA en cuanto al conocimiento del producto y los factores relacionados a la elección, periodicidad y cantidad de carne consumida. El diagnóstico se realizó a través de entrevistas con formularios en línea. Se ha preferido el consumo de carne de vacuno y de pescado, y la carne de búfalo se ha mostrado menos consumida, pero una parte expresiva de la población afirmó estar dispuesta a aumentar este consumo. Los motivos para no consumir carne de búfalo se relacionaron con el hecho de ser una carne poco apreciada y falta de oferta. El desconocimiento de las formas de creación, procedencia, aspectos nutricionales, y posibles formas de comprar y preparar la carne de búfalo llevó a ratificar su bajo consumo local, además de la falta de oferta del mercado. Los consumidores de carne de búfalo consideran este un alimento sabroso y sano, sin embargo, poco ofertado en el mercado. Se sugieren campañas que tengan como objetivo el aumento de la oferta y el consumo de la carne de búfalos y en acciones que permitan a la población descubrir nuevas formas de preparación, consumo y más información nutricional.
\end{abstract}

Palabras clave: bubalinocultura, consumo de carne, productos procesados

\section{Introdução}

O consumidor possui papel essencial no comércio de produtos alimentícios, pois cabe a ele o poder de decisão ao final da cadeia produtiva (Williamson 2000). Dessa forma, a indústria necessita estar sintonizada às preferências de seu público alvo e, nesse contexto, a ciência e inovação desempenham papel fundamental para responder as preocupações e expectativas da sociedade (Troy \& Kerry 2010; Guerrero et al. 2013). Saber o que o consumidor deseja, permite um enfoque mais preciso em relação aos seus gostos e preferências, o que melhora a efetividade da produção em todos os elos da cadeia ( $\underline{\mathrm{Saab} \text { et }}$ al. 2009).

A carne de búfalo preenche as exigências do mercado consumidor atual, que procura uma alimentação saudável, e ao mesmo tempo, saborosa, de boa aparência e muito suculenta, sendo, portanto, mais indicada para a saúde humana. Segundo Jorge (1999) quando se compara a carne bubalina à bovina, a carne bubalina apresenta em média $40 \%$ menos colesterol; $55 \%$ menos calorias; 12 vezes menor de gordura; $11 \%$ mais de proteína e $10 \%$ mais de minerais. Segundo Marques et al. (2015), em estudos feito na cidade de Belém-PA sobre consumidores da carne de búfalos, uma pequena parcela dos entrevistados consome carne bubalina e os potenciais consumidores exibiram predisposição a inserir o produto em sua cesta de consumo. Mas, a pequena disponibilidade do produto no mercado e o baixo nível de informação referente aos seus benefícios têm limitado o crescimento da demanda.

Diante disso, este trabalho visou caracterizar o consumidor de carne bubalina, no município de Marabá-PA, quanto ao seu comportamento e percepções, além de aferir o seu nível de conhecimento sobre o produto, a intenção de compra e preferência quando comparado a carne bovina.

\section{Material e Métodos}

Optou-se por fazer neste trabalho, uma investigação amostral da população urbana de uma cidade a fim de identificar qual o comportamento desta população em relação às principais variáveis que afetam a quantidade demandada de um determinado bem. Para tanto, fez-se uma análise descritiva das características populacionais que levam ou não ao consumo do bem em questão.

O estudo foi realizado no município de Marabá, Pará, no período de maio a julho de 2017. O município se localiza na região Sudeste do estado do Pará. De acordo com a estimativa do Censo Demográfico de 2017, o município possui 271.594 habitantes.

As principais atividades econômicas do município são: a bovinocultura de corte, e comércio. O diagnóstico foi realizado por meio de entrevistas com consumidores, com a aplicação de questionários, via online, destinados aos moradores do município. 
As variáveis investigadas como condicionantes do volume demandado de leite e carne bubalina foram: preferência do tipo de carne, preferência por carne de búfalo, existe demanda e oferta da carne de búfalo no mercado, frequência de compra da carne de búfalo, quantidade da compra da carne de búfalo, preferência do tipo de corte da carne de búfalo, opinião sobre o modelo de comercialização, critérios para compra da carne de búfalo, consumo de iguarias, diferenciação do sabor da carne de búfalo/bovino.

Com o objetivo de garantir a representatividade da amostra foi planejada a aplicação dos questionários para se obter uma distribuição homogênea da população (baseada nos consumidores). Para calcular o número de pessoas entrevistadas utilizou-se o método de amostragem sem reposição para uma população finita, de acordo com Macfie et al. (1989). A equação possui nível de confiança de $99 \%$ e tolerância de erro amostral de $1 \%$. Equação: $n=(\mathrm{Z} 2$.p.q.N)/[d2 . $(\mathrm{N}-$ 1) $+\mathrm{Z} 2$.p.q ], Em que N representa o tamanho da população; $Z$ é a abscissa da curva normal padrão (2,576); p é a estimativa da verdadeira proporção de um dos níveis da variável escolhida (no caso, $p$ $=\mathrm{q}=0,5)$ e d é o erro amostral admitido.

Ao se considerar a população do município de Marabá, Pará, foi realizada 120 entrevistas durante dois meses. Para análise de dados utilizou-se a técnica de distribuição de frequência, que permite transformar dados brutos em informações traduzidas para interpretação e visualização das informações de fenômeno, e ilustra com percentuais o número de respostas feitas em uma pesquisa, o que facilita sua contagem.

\section{Resultados e discussão}

Verifica-se que a carne bovina foi a preferida para os entrevistados $(51,9 \%)$ (Figura 1). Quando se perguntou a respeito da preferência por carne de búfalo, 25,9\% afirmou que gosta deste tipo de carne; porém, a oferta continua pequena no município (Figura 1). Já o percentual de entrevistados que não gostam de carne de búfalos foi de $7,4 \%$. No entanto, $66,7 \%$ nunca comeu desse tipo de carne.

Diante disso, 22,2\% asseguram que o mercado disponibiliza a carne de búfalos esporadicamente (Figura 3). Segundo Silva and Nardi Junior (2014) afirmam que em cidades do norte do país apontam um consumo de carne bubalina ao redor de 10$15 \%$.

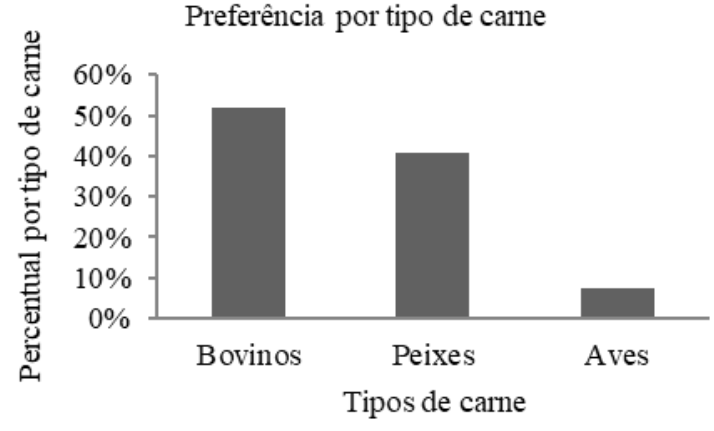

Figura 1. Percentual de preferência do tipo de carne para os entrevistados em Marabá - Pará, 2017

De acordo com Faria et al. (2006) a variável "preço" é uma das mais importantes a serem analisadas na demanda de qualquer produto, já que o consumidor, em condições normais de consumo, ao adquirir um produto procura sempre preços mais baixos. Entretanto, nesta pesquisa (Tabela 1) as principais razões apontadas como fatores para não consumir carne de búfalo in natura foram: falta de oferta $(29,6 \%)$ e falta de conhecimento $(63 \%)$.

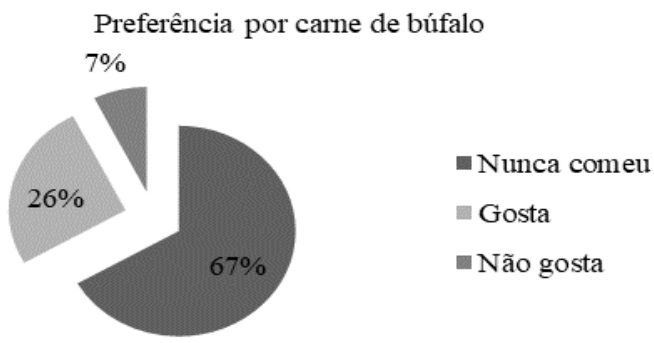

Figura 2. Percentual de preferência por carne de búfalos para os entrevistados em Marabá - Pará, 2017.

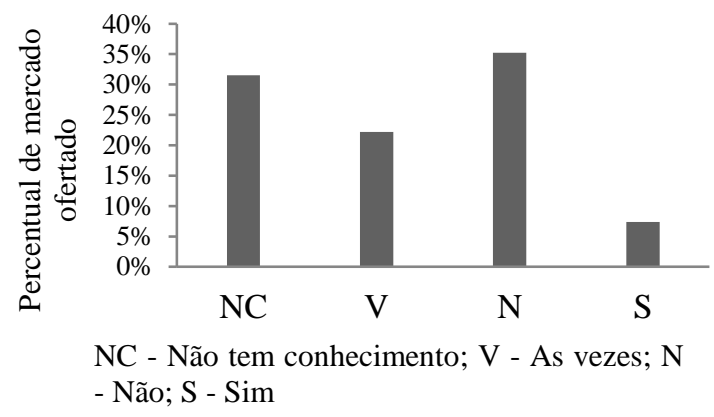

Figura 3. Percentual de oferta de mercado da carne de búfalos para os entrevistados em Marabá - Pará, 2017.

A razão de maior impacto para não consumir a carne suína (não apreciar) apontada pelos consumidores pode estar relacionada com questões culturais, as quais têm relação direta com a oferta de carnes local, quais sejam: carne bovina e peixes. 
Tabela 1. Razões pelas quais os entrevistados não consomem carne de búfalos

\begin{tabular}{lc}
\hline Razão & Percentagem (\%) \\
\hline Não tem conhecimento & 63 \\
Falta oferta no mercado & 29.6 \\
Não aprecia & 7,4 \\
\hline
\end{tabular}

Ao comparar com outras carnes, a carne de búfalo apresenta-se saborosa, de boa aparência e muito suculenta, sendo, portanto, mais indicada para a saúde humana. Quando se compara a carne bubalina à bovina, a carne bubalina apresenta em média $40 \%$ menos colesterol; 55\% menos calorias; 12 vezes menor de gordura; $11 \%$ mais de proteína e $10 \%$ mais de minerais (Oliveira et al., 2005).

\section{Conclusão}

O consumo de carne de búfalos é muito baixo no município de Marabá, Pará, sendo a carne bovina a preferida pelos consumidores. A carne de búfalo tem grande interesse pelos entrevistados, necessitando de maior oferta no município. Assim, é necessário melhorar o sistema de comercialização e divulgar as qualidades organolépticas da carne e dos produtos de origem bubalina.

\section{Referências bibliográficas}

Faria I.G., Ferreira J.M. \& Garcia S.K. 2006. Mercado consumidor de carne suína e derivados em Belo Horizonte, Brasil. Arquivo Brasileiro de Medicina Veterinária $e$ Zootecnia 58, 251-256.

Guerrero A., Valero M.V., Campo M.M. \& Sañudo C. 2013. Some factors that affect ruminant meat quality: from the farm to the fork. Review. Acta Scientiarum. Animal Sciences 35, 335-347.
Jorge A.M. 1999. Desempenho em confinamento e características de carcaça em bubalinos. Revista Nacional da Carne 1, 52-64.

Macfie H.J., Bratchell N., Greehoff K. \& Vallis L.V. 1989. Designs to balance the effect of order of presentation and first order carry over effect in hall tests. Journal of Sensory Studies 4, 129-148.

Marques C.S.S., Oaigen R.P., Moraes C.M., Santos M.A.S., Lourenço Júnior J.B. \& Bezerra I.A. 2015. Perfil dos consumidores da carne de búfalo, em Belém, Pará, Brasil. Acta Veterinaria Brasilica 9, 126-133.

Oliveira et al., 2005

Saab M.S.B.L., Neves M.F. \& Cláudio L.D.G. 2009. O desafio da coordenação e seus impactos sobre a competitividade de cadeias e sistemas agroindustriais. Revista Brasileira de Zootecnia 38, 412-422.

Silva S.L. \& Nardi Junior G. 2014. Produção de derivados bubalinos e mercado consumidor. Tekhne e Logos 5, 15-30.

Troy D.J. \& Kerry J.P. 2010. Consumer perception and the role of science in the meat industry. Meat Science 86, 214-226.

Williamson O.E. 2000. The new institutional economics: taking stock, looking ahead. Journal of Economic Literature 38, 595-613.

Recebido: 16 setembro, 2018.

Aprovado: 29 outubro, 2018.

Publicado: 27 dezembro, 2018.

Licenciamento: Este artigo é publicado na modalidade Acesso Aberto sob a licença Creative Commons Atribuição 4.0 (CC-BY 4.0), a qual permite uso irrestrito, distribuição, reprodução em qualquer meio, desde que o autor e a fonte sejam devidamente creditados. 